(C) 2021, The Authors. Published by Elsevier Inc. and Fass Inc. on behalf of the American Dairy Science Association ${ }^{\circledR}$. This is an open access article under the CC BY-NC-ND license (http://creativecommons.org/licenses/by-nc-nd/4.0/).

\title{
An observational study on the management of digital dermatitis through a repeated risk assessment on 19 Dutch dairy herds
}

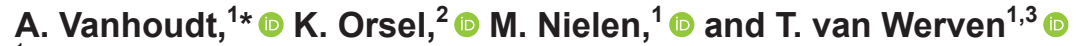 \\ ${ }^{1}$ Department of Population Health Sciences, Faculty of Veterinary Medicine, Utrecht University, $3584 \mathrm{CL}$, Utrecht, the Netherlands \\ ${ }^{2}$ Department of Production Animal Health, Faculty of Veterinary Medicine, University of Calgary, Calgary, AB, Canada, T2N 4N1 \\ ${ }^{3}$ University Farm Animal Practice, 3481 LZ, Harmelen, the Netherlands
}

\begin{abstract}
The etiopathogenesis of bovine digital dermatitis (DD) is not well understood, but its risk factors on dairy farms have been studied extensively. The objective of this study was to identify associations between a DD risk score [determined by a DD risk assessment questionnaire (RAQ)] and DD prevalence (determined by an in-parlor M-score). We also investigated whether feedback for farmers on their DD management using the DD RAQ resulted in changes that decreased DD prevalence in their herds. The DD RAQ consisted of multiple-choice questions related to foot health, housing, and general management that were used to create a total risk score (TRS). In 2016 and 2018, the DD $\mathrm{RAQ}$ - together with a DD prevalence determination in the lactating herd - was used on 19 Dutch dairy farms from 1 veterinary practice. After each visit, farmers and their consulting veterinarians received a 1-page summary that identified herd-specific strengths and weaknesses in DD management. In 2018, the summary included suggestions for improvement. In 2019, farmers and veterinarians were contacted to ask whether the use of the DD RAQ and the 1-page summary had led them to implement changes in their DD management in 2016 and 2018. We tested the association between TRS and DD prevalence using linear mixed model analysis. The TRS ranged from 13 to $65 \%$ and 20 to $68 \%$ in 2016 and 2018, respectively. Herd DD prevalence ranged from 15 to $59 \%$ and 27 to $69 \%$ in 2016 and 2018, respectively. For both years, the DD RAQ identified that DIM, herd size, and breed were often present in a manner associated with increased risk for DD. The linear mixed model analysis identified that each 10-point increase in TRS was associated with an increase in herd DD prevalence of less than $1 \%$. The association between TRS and herd DD prevalence was caused mainly by
\end{abstract}

Received April 16, 2020.

Accepted August 16, 2020.

*Corresponding author: a.vanhoudt@uu.nl risk factors related to housing. We found no important relationship between change in TRS and change in DD prevalence between the 2 visits. Only a few farmers indicated some form of change in their DD management following a visit. Veterinarians in general said that they discussed the 1-page summaries and DD control with farmers during a routine visit, but the majority admitted a lack of follow-up. We propose that the DD RAQ could be used as a tool to start a discussion on DD control on farm, but simply undertaking a DD RAQ and providing a 1-page summary of the results was insufficient to initiate behavioral change that led to a decrease in DD prevalence.

Key words: behavioral change, dairy cow, digital dermatitis, questionnaire, risk factor

\section{INTRODUCTION}

Following its first description by Cheli and Mortellaro (1974), digital dermatitis (DD) quickly became recognized as the most important infectious cause of lameness in dairy cattle. Because certain lesion stages are painful, DD has a negative effect on cattle productivity and welfare worldwide (Bruijnis et al., 2012; Higginson Cutler et al., 2013; Dolecheck and Bewley, 2018).

The etiology of DD is probably polybacterial, with lesions consistently containing large numbers of multiple Treponema spp. together with a multitude of other bacteria, such as Dichelobacter nodosus, Fusobacterium necrophorum, Mycoplasma fermentans, and Porphyromonas levii (Krull et al., 2014; Nielsen et al., 2016; Moreira et al., 2018). Treponema spp. and non-treponema bacterial populations do not appear randomly: they are associated with specific lesion stages and change with lesion progression (Krull et al., 2014; Zinicola et al., 2015; Beninger et al., 2018). Current treatment and control strategies focus on dealing with this bacterial load, but to date they have been unsuccessful in eradicating the disease from most herds (Yeruham and Perl, 1998). Generally, they result in an endemic balance, with a more or less stable prevalence and the majority 
of lesions remaining at the chronic M4 stage (Döpfer and Bonino Morlán, 2008; Biemans et al., 2018).

Understanding risk factors and control measures as reviewed for DD by Potterton et al. (2012), Palmer and O'Connell (2015), and Cook (2017) provides valuable insight in the epidemiology of an infectious disease. However, little is known about how to translate this knowledge into an effective DD control plan. Two studies from the United Kingdom investigated DD prevalence reduction as part of a general lameness control program (Bell et al., 2009; Barker et al., 2012), and 1 Canadian study specifically focused on DD prevalence in a controlled footbath intervention program (Solano et al., 2017b). The intervention studies of Bell et al. (2009) and Barker et al. (2012) failed to reduce DD prevalence. As important reasons for this outcome, the authors identified poor compliance with advice, a mismatch between the applied communication method and farmer type, and insufficient time to implement changes with significant effect. In contrast, Solano et al., 2017b achieved a reduction in both active DD lesion stages and DD prevalence in herds with a high $(\geq 15 \%)$ prevalence of active DD lesions with a controlled intervention study that implemented best-practice foot bathing.

Our study investigates the effect of raising awareness with a DD-specific risk assessment on the prevalence of DD in dairy herds, leaving 2 years to implement changes with measurable effect. We conducted a repeated cross-sectional field study with a DD risk assessment questionnaire (RAQ) and DD prevalence determination through in-parlor M-scoring on Dutch dairy farms with routine herd health advice, using each farm as a historical control. The objectives of this study were (1) to identify associations between a DD risk score determined by the DD RAQ and DD prevalence; and (2) to investigate whether feedback on DD management through the DD RAQ resulted in management changes that decreased DD prevalence in herds.

\section{MATERIALS AND METHODS}

\section{Ethical Statement}

This study was performed in accordance with European law concerning the protection of animals kept for farming purposes (Council Directive 98/58/EC) and was not considered an animal experiment under Dutch legislation. The farmers participated in the research based on an informed consent statement. The veterinarians participated under the teaching agreement between the University Farm Animal Practice and the Faculty of Veterinary Medicine of Utrecht University, all within current Dutch legislation on non-medical research on human subjects.

\section{Data Collection}

Herd Selection. In 2016, a convenience sample of 22 herds was selected from the dairy herds ( $\mathrm{n}=$ 330) served by the University Farm Animal Practice (Harmelen, the Netherlands). The veterinarians from this practice were asked to compile a list of clients that would meet the following selection criteria: a herd with a DD problem in the previous months according to the herd's veterinarian; and a milking parlor suitable for in-parlor M-scoring. Farmers from this list were then contacted and asked if they were willing to participate in the study until a total of 22 participants was reached. Of these 22 herds, 19 farmers also agreed to participate in the 2018 DD RAQ and farm visit. Dropout reasons were as follows: stopped farming; ongoing transition to organic farming; and did not see the value of participating further in the study. The DHI data were extracted from farm-management software with the consent of the participating farmers (pirDAP, the Netherlands).

$D D R A Q$. The DD RAQ was an interim version of the lameness RAQ developed and validated by the University of Calgary (van Huyssteen et al., 2020). The DD RAQ consisted of 22 multiple-choice questions and was composed of sections on foot health, housing, and general herd management $(5,8$, and 9 questions, respectively; Supplemental Data File S1; https:/ /doi.org/10.3168/jds.2020-18730). Each of the answers to the questions was given a risk score based on the published literature; higher scores indicated a higher risk for DD. The risk scores were summed for a total risk score (TRS) with a maximum of 580; foot health contributed $22 \%$, housing $28 \%$, and general herd management $50 \%$. The DD RAQ was conducted during the farm visit by 2 veterinary students ( $\mathrm{NH}$ in 2016 and NW in 2018).

Animal-Based Measures. The washed hind feet of the lactating animals were inspected in the milking parlor to score DD using the M-score (Döpfer et al., 1997; Relun et al., 2011; Berry et al., 2012; Solano et al., 2017a). During the same milking, the leg hygiene of whichever hind limb was facing the scorer in the milking parlor was also scored (Schreiner and Ruegg, 2002; Cook, 2006; Solano et al., 2015).

Scorer Training. Veterinary students NH and NW were trained by AV in applying the M-score and the leg hygiene score. Training on the M-score was done by a study of the literature, classroom training (39 digital color photographs of cattle feet with varying M-stages provided by $\mathrm{KO}, 46 \%$ agreement between $\mathrm{NH}$ and 
NW), and 1 in-parlor M-scoring of the washed hind feet of approximately 50 dairy cows together with AV. Leg hygiene score training consisted of studying the score definitions, followed by in-parlor scoring of 1 lower hind limb of approximately 50 dairy cows under supervision of AV during the in-parlor M-score training.

Farm Visits, Group Meetings, and One-Page Summaries. In February 2016, all farmers $(\mathrm{n}=22)$ and their consulting veterinarians $(\mathrm{n}=9)$ were invited for a meeting on DD. The study design and details about data collection methods, together with a brief overview of how to control DD on dairy farms, were presented. Farms were then visited once in 2016 and once in 2018 - in March or April while the dairy herd was housed. During the farm visit, the scorer went through the DD RAQ with the farmer, measured housing parameters (e.g., cubicle type, length, and width), and joined 1 milking session to perform the in-parlor M-score and leg hygiene score. The sensitivity and specificity of the in-parlor dichotomized M-score compared with scoring of raised feet in the trimming chute were 0.58 to 0.92 and 0.80 to 0.95 , respectively (Relun et al., 2011; Solano et al., 2017a; Cramer et al., 2018). We were unable to obtain M-scores on a small number of cows for 1 or both hind limbs because of their behavior, foot conformation, or the presence of a bandage (n $=82$ cows). At the end of the farm visit, farmers were given a list of cows that were scored with an M2-stage lesion and were eligible for treatment. In 2016, 1-page summaries were compiled and emailed to the farmer and consulting veterinarian after all farm visits were completed. In 2018, 1-page summaries were compiled and emailed to the farmer and consulting veterinarian within $14 \mathrm{~d}$ of each farm visit. In July 2018, farmers (19) and veterinarians (10) were again invited for a group meeting, where anonymized results of the study were presented.

\section{Follow-Up Questionnaire}

In November 2019, we emailed farmers $(\mathrm{n}=19)$ and their consulting veterinarians $(\mathrm{n}=11)$ from 2016, 2018, or both years and asked them to indicate whether or not the DD RAQ and 1-page summary had resulted in implementation of changes to their DD management in 2016, 2018, or both years. We sent a reminder email in January 2020, and 1 veterinarian was approached once more to complete the follow-up questionnaire.

\section{Data Handling and Statistical Analyses}

Data were collected using pencil and paper, the RAQ, and scoring sheets, and collated into a digital spread- sheet (MS Excel; Microsoft, Redmond, WA). The 2016 DD RAQ and M-score data from the 3 herds that did not participate in 2018 were excluded from the analyses. Each herd's TRS was converted to a percentage score by dividing the TRS by the maximum risk score that could have been achieved from the questions that were answered. The in-parlor M-scores for hind limbs were transformed to a dichotomized (absence and presence) cow-level DD prevalence for each herd. Within each herd, M-scores were also grouped into 3 cow-level DD categories: cows without DD on both hind feet (DD$\mathrm{M} 0$ ), cows with at least $1 \mathrm{M} 2$-stage lesion (DD-M2), and cows with DD but no M2-stage lesion (DD-other). Cows with M0 on 1 hind foot and "unable to score" on the other hind foot, and cows with "unable to score" on both hind feet, were excluded from the analyses $(\mathrm{n}=$ 53 cows).

We calculated descriptive statistics for TRS and herd DD prevalence. We tested the association between TRS (as absolute score divided by 10 for ease of interpretation) and DD prevalence (as a percentage) using linear mixed model analyses with (1) TRS as the predictor and DD prevalence measures as the outcome; and (2) TRS sections (foot health, housing, and general management) as predictors and DD prevalence measures as the outcome. In both linear mixed models, we used the year of the DD RAQ as a fixed effect and herd as a random effect.

We explored the association between $\Delta$ TRS (2018 vs. 2016) as the predictor and $\Delta$ DD prevalence (2018 vs. 2016) as the outcome using a scatter plot to identify the effect of the $2016 \mathrm{DD}$ RAQ and 1-page summary on DD prevalence in 2018. We performed all statistical analyses in SPSS 25.0.0.1 (IBM Corp., New York, NY).

\section{RESULTS}

\section{DD Risk Assessment Questionnaire and DD Prevalence}

An overview of the results of the TRS and DD prevalence for 2016 and 2018 is provided in Figure 1. Details for these variables can be found in Supplemental Table S1 (https://doi.org/10.3168/jds.2020-18730). Table 1 provides a summary of the answers for a selection of questions from the DD RAQ. In 2016, the TRS varied between 13 and $65 \%$ (mean \pm standard deviation $42 \pm$ $13 \%$ ), and herd DD prevalence ranged from 15 to $59 \%$ $(39 \pm 14 \%)$. In 2018, the TRS varied between 20 and $68 \%(41 \pm 13 \%)$ and herd DD prevalence ranged from 27 to $69 \%(49 \pm 10 \%)$. Note the high prevalence of cows with M2-stage lesions in herd 17 in 2018 (Figure $1 b)$. 
Linear mixed model analysis identified that herd DD prevalence was approximately $10 \%$ higher in 2018 than in 2016 [95\% confidence interval (CI) 4.51-16.29; Table 2]. Using TRS and DD data from both DD RAQ years, we found that each 10-point increase in TRS was associated with an increase in herd DD prevalence of less than $1 \%(0.63,95 \%$ CI $0.05-1.22)$. This association disappeared for the prevalence of DD-M2 cows, but remained a trend for the prevalence of DD-other cows (0.59, 95\% CI -0.007 to 1.18$)$. Linear mixed model analysis with TRS section scores indicated that the section score for housing had the most influence on the DD prevalence outcomes relative to the section scores for foot health and general management.

In the herds with lowest herd DD prevalence, manure scraping was automatic or robotic; cows had at least 8 $\mathrm{h}$ access to pasture during the grazing season with a cow track of at least $150 \mathrm{~m}$; the lactating herd size was less than 90 cows; and a maximum $85 \%$ of the lactating herd was 100\% Holstein Friesian. These responses all had a risk score of 0 on the RAQ. In the herds with the highest herd DD prevalence, more than $85 \%$ percent of the lactating herd was 100\% Holstein Friesian; $80 \%$ or more of the lactating herd was more than 60 DIM; and the lactating herd size was 90 cows or more. These responses all had a maximum risk score on the RAQ.

The changes in TRS and herd DD prevalence from 2018 to 2016 are visualized in Figure 2. In 4 herds, both TRS and herd DD prevalence increased at least $5 \%$, and in 4 herds TRS decreased at least $5 \%$ and herd DD prevalence increased at least $5 \%$. In these 8 herds, changes in TRS originated from changes in the general management section. In herd 19, both TRS and herd DD prevalence decreased at least $5 \%$. The scatter plot
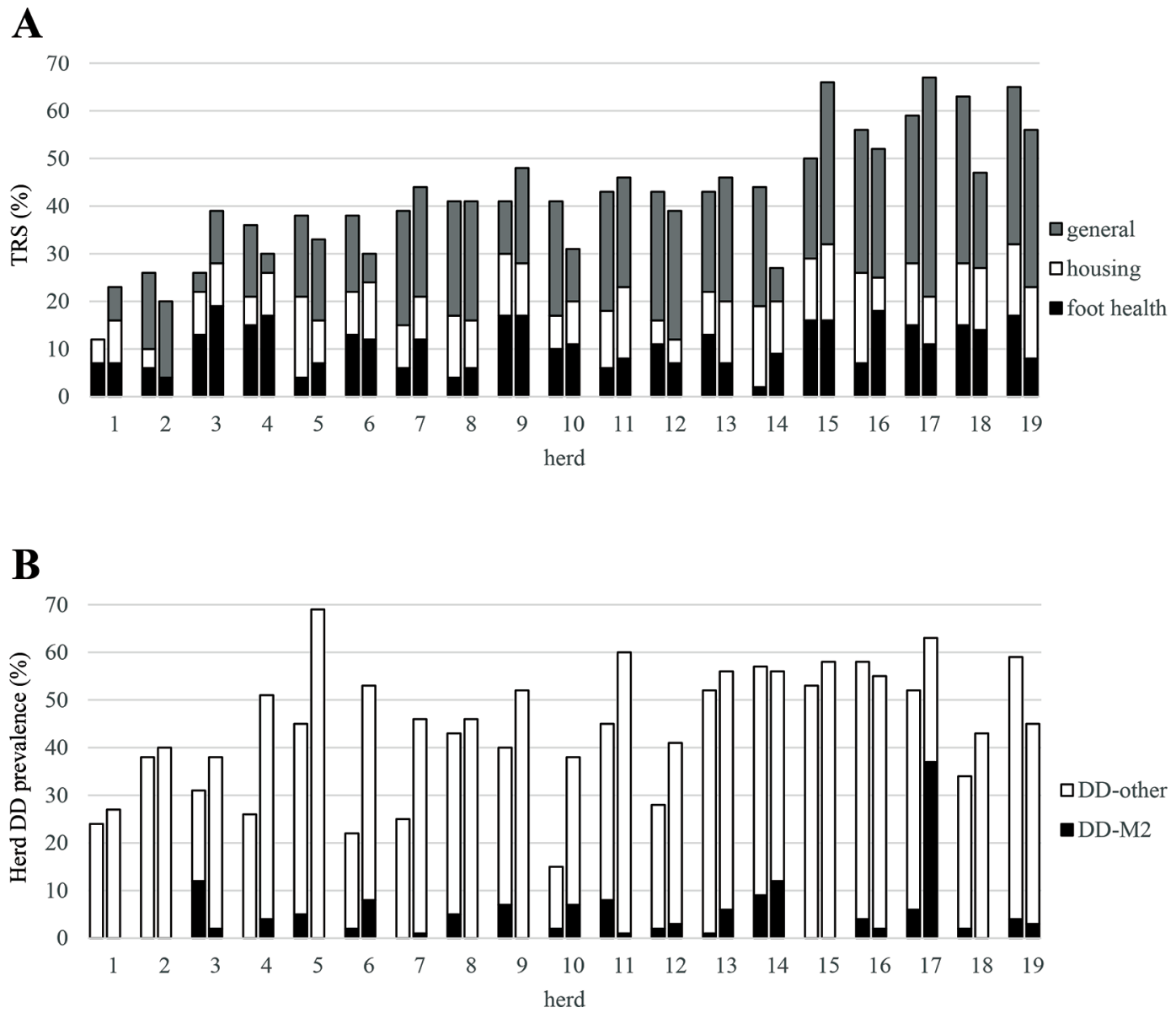

Figure 1. An overview of (a) the total risk score (TRS) and its components as percentage derived from a digital dermatitis (DD) risk assessment questionnaire and (b) cow-level herd DD prevalence and its composing DD categories (DD-M2 for cows with at least 1 M2-stage lesion and DD-other for cows with DD but no M2-stage lesion) from the washed, hind feet, in-parlor M-score (Berry et al., 2012) for 19 Dutch dairy herds visited once in 2016 and once in 2018. Herds are ordered from low to high TRS in 2016; for each herd, the left bar represents 2016 and the right bar represents 2018. 
Table 1. Summary of the answers from 19 Dutch dairy herds on a selection of questions from a digital dermatitis risk assessment questionnaire

\begin{tabular}{|c|c|c|c|c|}
\hline $\begin{array}{l}\text { Question topic } \\
\text { (question number) }\end{array}$ & $\begin{array}{l}\text { Risk } \\
\text { score }\end{array}$ & Answer options & \multicolumn{2}{|c|}{ Herds (no.) } \\
\hline \multirow[t]{2}{*}{ Leg hygiene score (1) } & 30 & $>75 \%$ score $3-4$ & 2 & 4 \\
\hline & 10 & $>75 \%$ score $1-2$ & 10 & 0 \\
\hline \multirow[t]{2}{*}{ Foot trimming schedule $^{1}(2)$} & 30 & Only lame cows & 6 & 6 \\
\hline & 0 & Routine whole herd & 9 & 11 \\
\hline \multirow[t]{4}{*}{ Foot bathing schedule (5) } & 40 & No foot bathing & 10 & 8 \\
\hline & 30 & Interval $>4 \mathrm{wk}$ & 0 & 1 \\
\hline & 15 & Every $4 \mathrm{wk}$ & 2 & 2 \\
\hline & 0 & Every 2 wk & 7 & 8 \\
\hline Manure scraping method ${ }^{2}(10)$ & 0 & Robotic scraping & 8 & 9 \\
\hline \multirow[t]{2}{*}{ Breed of the lactating herd (15) } & 50 & $>85 \%$ was $100 \%$ Holstein Friesian & 11 & 13 \\
\hline & 0 & $\leq 85 \%$ was $100 \%$ Holstein Friesian & 8 & 6 \\
\hline \multirow[t]{3}{*}{ Purchase of cattle (18) } & 40 & $>10 \%$ of lactating herd during the previous $12 \mathrm{mo}$ & 3 & 1 \\
\hline & 10 & $1-5 \%$ of lactating herd during the previous $12 \mathrm{mo}$ & 1 & 1 \\
\hline & 0 & No purchase during the previous $12 \mathrm{mo}$ & 15 & 17 \\
\hline \multirow[t]{5}{*}{ Cubicle bedding type ${ }^{3}$} & NA & Rubber mat with $<2 \mathrm{~cm}$ top dressing & 10 & 10 \\
\hline & NA & Cow mattress with $<2 \mathrm{~cm}$ top dressing & 3 & 3 \\
\hline & NA & Concrete with $>2 \mathrm{~cm}$ top dressing & 2 & 2 \\
\hline & NA & Waterbed with $<2 \mathrm{~cm}$ top dressing & 2 & 2 \\
\hline & NA & Half concrete, half rubber, both with $<2 \mathrm{~cm}$ top dressing & 1 & 1 \\
\hline
\end{tabular}

${ }^{1}$ More than 1 answer possible; lowest risk score was used when multiple answer options were given.

${ }^{2}$ The answer for 1 or more herds was missing.

${ }^{3}$ Additional information gathered during the farm visit. $\mathrm{NA}=$ not applicable.

demonstrates that we found no important relationship between $\Delta$ TRS as the predictor and $\Delta$ DD prevalence as the outcome (Figure 3).

\section{One-Page Summaries}

In 2016 and 2018, 1-page summaries described overall findings from the study and provided farm-specific risk factors. In 2018, the summaries also provided suggestions for enhancement of the herd's DD management. For both years, the DD RAQ identified that DIM, lactating herd size, and breed were often present in a manner associated with increased risk for $\mathrm{DD}$, and that few herds purchased cattle. "Improve overall hygiene and leg hygiene" was most frequently suggested to ameliorate DD management, followed by "Introduce breeds known to be less susceptible to DD" (18 and
12 times, respectively). "Disinfect foot trimming equipment" and "Implement a footbath" were other frequent suggestions ( 7 and 5 times, respectively).

\section{Follow-Up Questionnaire}

The response rate for the follow-up questionnaire was $53 \%$ for farmers and $100 \%$ for veterinarians. Four farmers indicated some form of change in their DD management in 2016, and 7 farmers indicated change in 2018. Increasing the foot bathing regimen, ensuring prompt treatment of affected cows, and improving hygiene through manure scraping and disinfection of foot trimming equipment were changes made. In general, veterinarians said that they discussed the 1-page summaries and DD control with the farmer during a routine visit, but the majority admitted lack of follow-up. 


\section{DISCUSSION}

We identified a small association between a higher TRS and a higher herd DD prevalence. This association was mainly explained by risk factors in the housing section of the RAQ (all related to exposure to infectious fecal material) rather than by risk factors in the foot health section. This may be because foot trimming practices are related to foot health in general, instead of specific to DD prevalence. It could also be that foot bathing practices used by the herds in our study did not comply with what is currently considered to be best practice (Cook, 2017; Solano et al., 2017b). Unfortunately, details about foot bathing practices were not included in the DD RAQ. The small association we

Table 2. Results from linear mixed model analyses testing the association between total risk score (TRS) or its sections and digital dermatitis (DD) prevalence in 19 Dutch dairy herds visited once in 2016 and once in $2018^{1}$

\begin{tabular}{|c|c|c|c|}
\hline \multirow[b]{2}{*}{ Item } & \multirow[b]{2}{*}{ Estimate } & \multicolumn{2}{|c|}{$95 \% \mathrm{CI}$} \\
\hline & & Lower & Upper \\
\hline \multicolumn{4}{|l|}{ Herd DD prevalence } \\
\hline Intercept & 35.28 & 21.31 & 49.25 \\
\hline TRS & 0.63 & 0.05 & 1.22 \\
\hline 2018 vs. 2016 & 10.40 & 4.51 & 16.29 \\
\hline \multicolumn{4}{|l|}{$\mathrm{DD}-\mathrm{M} 2^{2}$ prevalence } \\
\hline Intercept & 1.74 & -6.25 & 9.72 \\
\hline TRS & 0.13 & -0.21 & 0.46 \\
\hline 2018 vs. 2016 & 0.97 & -3.24 & 5.19 \\
\hline \multicolumn{4}{|l|}{ DD-other ${ }^{3}$ prevalence } \\
\hline Intercept & 31.79 & 17.62 & 45.96 \\
\hline TRS & 0.59 & -0.007 & 1.18 \\
\hline 2018 vs. 2016 & 9.48 & 2.94 & 16.01 \\
\hline \multicolumn{4}{|l|}{ Herd DD prevalence } \\
\hline Intercept & 30.59 & 16.04 & 45.13 \\
\hline Foot health & 0.18 & -1.21 & 1.56 \\
\hline Housing & 2.68 & 0.94 & 4.42 \\
\hline General management & 0.28 & -0.43 & 0.99 \\
\hline 2018 vs. 2016 & 11.23 & 5.20 & 17.26 \\
\hline \multicolumn{4}{|l|}{ DD-M2 prevalence } \\
\hline Intercept & 3.15 & -6.06 & 12.35 \\
\hline Foot health & -0.29 & -1.19 & 0.61 \\
\hline Housing & 0.20 & -0.94 & 1.35 \\
\hline General management & 0.19 & -0.28 & 0.65 \\
\hline 2018 vs. 2016 & 1.20 & -3.03 & 5.42 \\
\hline \multicolumn{4}{|l|}{ DD-other prevalence } \\
\hline Intercept & 26.82 & 11.56 & 42.09 \\
\hline Foot health & 0.45 & -1.01 & 1.92 \\
\hline Housing & 2.53 & 0.69 & 4.38 \\
\hline General management & 0.13 & -0.62 & 0.89 \\
\hline 2018 vs. 2016 & 10.08 & 3.48 & 16.68 \\
\hline
\end{tabular}

${ }^{1}$ Total risk score is expressed as absolute score divided by $10 ;$ DD prevalence is expressed as percentage; year of the questionnaire was a fixed effect, and herd was a random effect.

${ }^{2}$ Cows with at least 1 M2-stage lesion from a washed, hind feet, inparlor M-score (Berry et al., 2012).

${ }^{3}$ Cows with DD but no M2-stage lesion from a washed, hind feet, inparlor M-score. observed between TRS and herd DD prevalence did not seem driven by the small proportion of cows with M2stage lesions, but rather by the majority of cows with other M-stage lesions, mostly M4-stage. Because cows with M4-stage lesions play an important role in the DD transmission dynamics in a herd, TRS combined with herd DD prevalence can be used to identify herdspecific improvement opportunities for DD control.

We identified a higher herd DD prevalence in 2018 than in 2016. A similar trend in DD prevalence was seen in the voluntary national Dutch database of foot trimming records [personal communication, Pieter van Goor (Arnhem, the Netherlands); DigiKlauw, CRV (Arnhem, the Netherlands) and Royal GD (Deventer, the Netherlands)]. A possible explanation for the lack of decrease in herd DD prevalence as a consequence of the DD RAQ is the study design. The 1-page summaries identified herd-specific risk factors for DD and contained noncommittal improvement options for DD management. Whether or not these items were addressed relied on the farmers and their consulting veterinarians. The majority of veterinarians in our study discussed the 1-page summaries with their clients but did not follow up after the initial discussion. A recent intervention study on foot bathing regimens reported that implementation of best-practice foot bathing by researchers resulted in improved control of DD on dairy farms with a high $(\geq 15 \%)$ prevalence of active DD lesions (Solano et al., 2017b).

The selection criterion "willingness to participate in the study" probably resulted in the selection of more progressive farmers who likely perceived DD as a problem in their herd and were eager to learn about the disease and how to control it. Still, only 4 of 10 farmers who answered the follow-up questionnaire changed their DD management in 2016. Unfortunately, none of the farmers in our study explained why they did not change their DD management. One veterinarian indicated that farmers had ample reasons for not implementing advice when they were asked why they did not make changes. Relun et al. (2013) state that the main barriers for French dairy farmers in adopting individual or collective DD treatments were required time and labor, followed by cost. Likewise, Bruijnis et al. (2013) identified labor efficiency and a long wait before seeing an improvement as possible barriers, and cost-effective measures as the main driver for achieving better foot health in a study with Dutch dairy farmers. Insufficient time to implement recommended changes that had a significant effect on foot health was one of the reasons for failure of the lameness control plan for heifers in dairy farms from the United Kingdom (Bell et al., 2009). Similar barriers to implementing changes 
or control strategies were also identified for Johne's disease (Roche et al., 2019). We refer the readers to the review by Ritter et al. (2017) for more information on the sociophysiological drivers for adoption of management strategies for infectious diseases by farmers.

The risk score for the questions in the DD RAQ used in this study ranged from 0 (low) to 60 (high) risk points, but in the lameness RAQ eventually developed by the University of Calgary (van Huyssteen et al., 2020), each question was given a risk score of 0 (low) to 3 (high). Both approaches resulted in systematic identification of areas and farms at high risk for DD based on the best knowledge available at the time of developing the RAQ. The DD RAQ can be used to monitor trends and allows for benchmarking within and between herds. The most likely application of the DD RAQ would be to help advisors raise awareness of the current risk for DD in a given herd. Incorporating risk factors such as DIM, herd size, and predominant breed can still be useful for identifying risk intensity, allowing the farmers to tailor their overall DD control management even though the specific risks cannot be managed. By applying a semi-qualitative tool such as the DD RAQ, interviewers can approach the topic with respect for the attitudes and beliefs of the respondents, who are encouraged to take part in the discussion and indicate what they feel is important (Braun and Clarke, 2013).

Two veterinary students collected the data for this study. Although they were both trained equally, observer bias may have occurred between 2016 and 2018 for farm characteristics and for M-scores. We found moderate agreement between the 2 students for $\mathrm{M}$ scores. With dichotomization of the M-score into the presence or absence of $\mathrm{DD}$, which has almost perfect inter-observer agreement (Vanhoudt et al., 2019), we likely kept the effect of this bias to a minimum.
We ascertained no important relationship between the change in TRS and the change in DD prevalence. Most current DD treatment and control measures are aimed at transition to or maintenance at the manageable M4 stage (Döpfer and Bonino Morlán, 2008). Because the M4 stage is the most important driver for transmission of DD (Biemans et al., 2018), it is a probable explanation for the lack of an association between the change in TRS and the change in DD prevalence in our study. Within each herd, the prevalence of DD remains relatively stable and appears to vary around an endemic balance. With current DD management focused mainly on maintaining relatively low levels of the often painful M2-stage lesions by early detection and prompt treatment, the welfare of affected cows is looked after; however, transmission of the disease through M4-stage lesions continues, leading to a herdspecific endemic balance. We therefore suggest that all stages of DD, like all affected production groups, be considered in the management of DD when aspiring to reduce DD prevalence.

\section{CONCLUSIONS}

The DD RAQ can be used to identify herd-specific risk factors for DD and raise awareness of strong and weak points for DD control on dairy farms. However, as a standalone intervention the DD RAQ is insufficient to initiate behavioral change from farmers and their consulting veterinarians that results in a decrease in DD prevalence under field conditions. Identifying drivers for the adoption of DD management strategies by farmers, together with an integrated approach that deals with all stages of DD in all affected production groups, is needed for a decrease in DD prevalence and improved control of the disease.

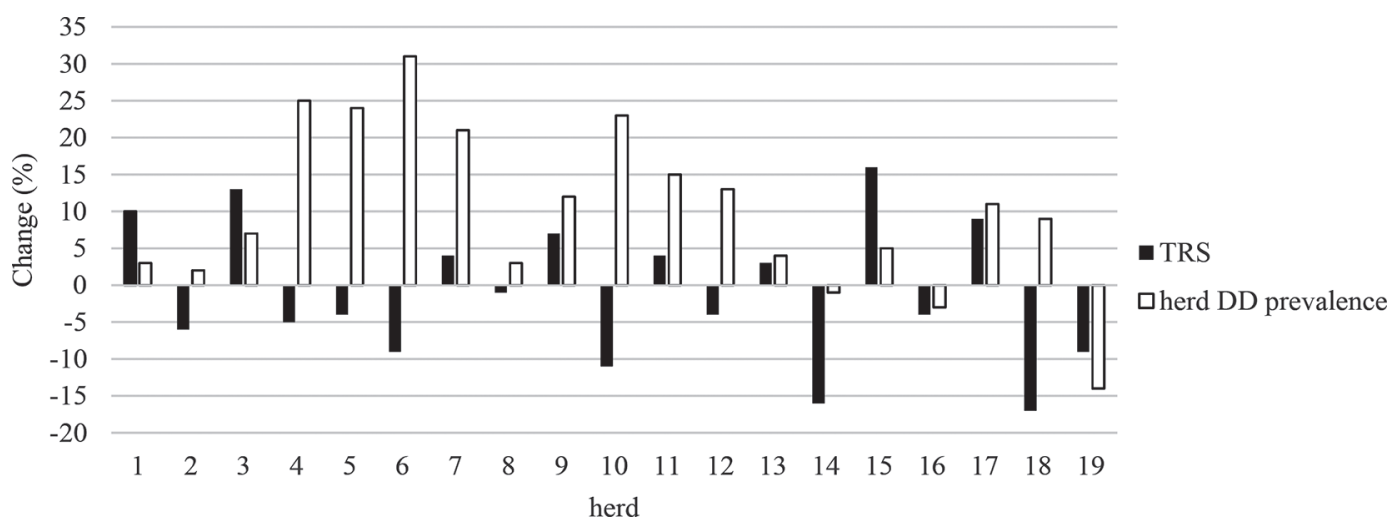

Figure 2. Changes (2018 to 2016) in total risk score (TRS; as a percentage) and cow-level herd digital dermatitis (DD) prevalence following a DD risk assessment questionnaire and associated 1-page summary for 19 Dutch dairy herds visited once in 2016 and once in 2018. Herds are ordered from low to high TRS in 2016. 
A

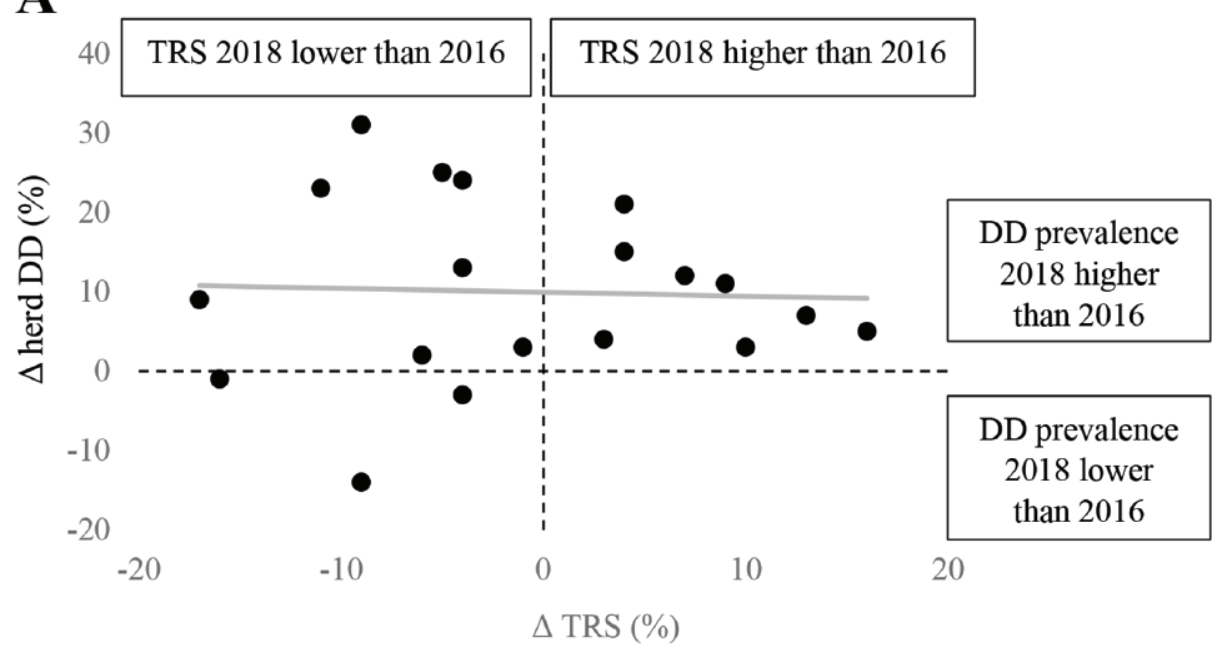

B

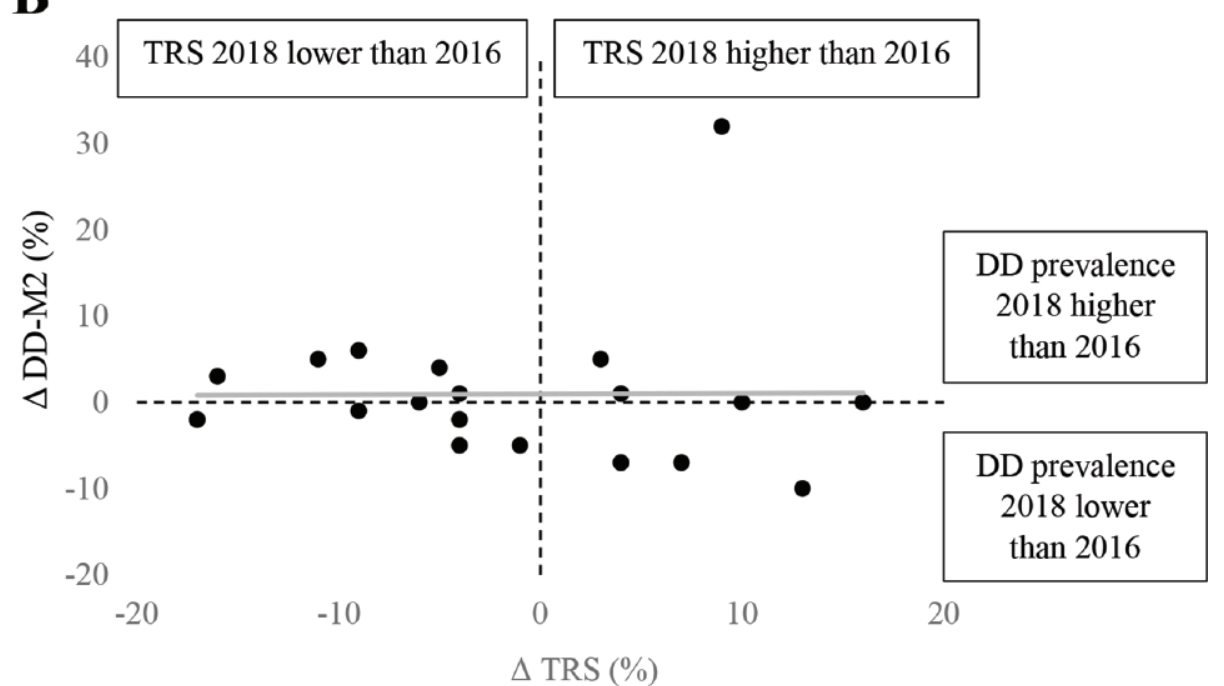

C

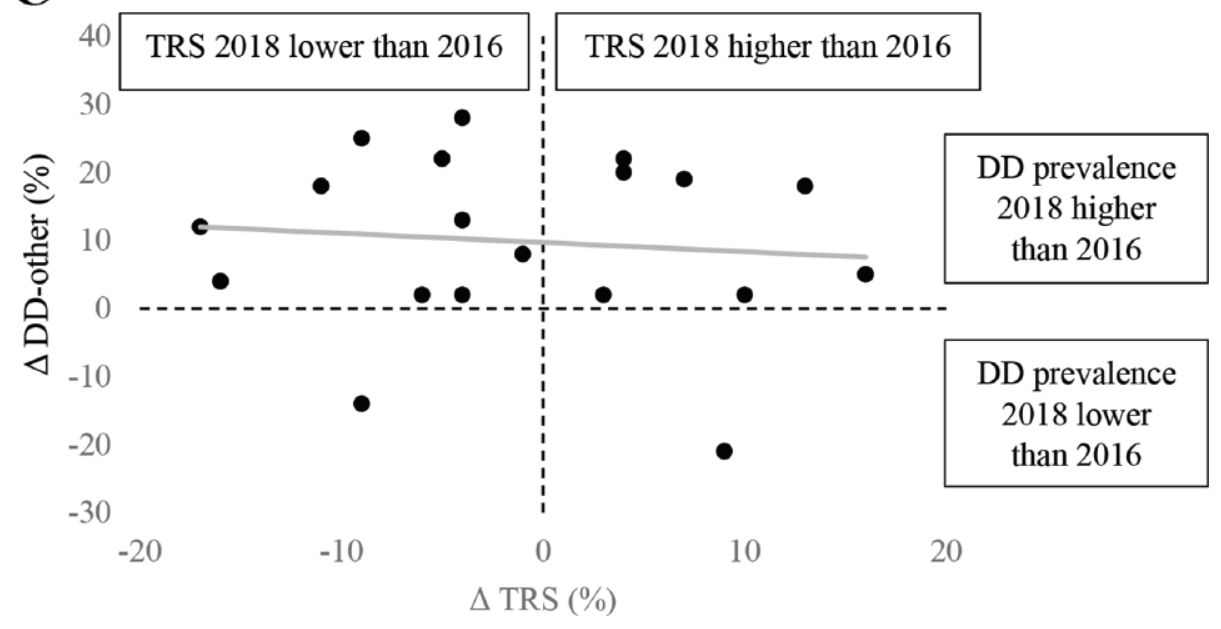

Figure 3. Scatter plot with a solid linear trendline visualizing the association between the difference (2018 to 2016$)$ in total risk score ( $\Delta$ TRS) as a predictor and the difference in (a) cow-level herd digital dermatitis prevalence ( $\Delta$ herd DD), (b) the prevalence of cows with at least 1 M2-stage lesion ( $\Delta$ DD-M2), and (c) the prevalence of cows with digital dermatitis but no M2-stage lesion ( $\Delta$ DD-other) as outcomes for 19 Dutch dairy herds visited once in 2016 and once in 2018. 


\section{ACKNOWLEDGMENTS}

The authors thank the farmers and veterinarians for their cooperation in this study, veterinary students $\mathrm{NH}$ and NW for their work collecting the data, Steven Sietsma (University Farm Animal Practice, Harmelen, the Netherlands) for his help in coordinating the study, Nick Bell (University of Nottingham, UK) for his critical mind and constructive feedback, and Gerrit Hooijer (Utrecht University, the Netherlands) for supervising $\mathrm{NH}$ during the study. AV prepared the dataset for analysis, performed the statistical analyses and wrote the manuscript; all other authors contributed to the manuscript; $\mathrm{KO}$ and $\mathrm{AV}$ designed the study. All authors declare that they have no conflict of interest related to the study discussed in this manuscript.

\section{REFERENCES}

Barker, Z. E., J. L. Wright, R. W. Blowey, J. R. Amory, and L. E. Green. 2012. Uptake and effectiveness of interventions to reduce claw lesions in 40 dairy herds in the UK. Anim. Welf. 21:563-576. https://doi.org/10.7120/09627286.21.4.563.

Bell, N. J., M. J. Bell, T. G. Knowles, H. R. Whay, D. J. Main, and A. J. F. Webster. 2009. The development, implementation and testing of a lameness control programme based on HACCP principles and designed for heifers on dairy farms. Vet. J. 180:178-188. https:// doi.org/10.1016/j.tvjl.2008.05.020.

Beninger, C., S. A. Naqvi, S. Naushad, K. Orsel, C. Luby, H. Derakhshani, E. Khafipour, and J. De Buck. 2018. Associations between digital dermatitis lesion grades in dairy cattle and the quantities of four Treponema species. Vet. Res. 49:111. https://doi.org/10 $.1186 / \mathrm{s} 13567-018-0605-\mathrm{z}$.

Berry, S. L., D. H. Read, T. R. Famula, A. Mongini, and D. Döpfer. 2012. Long-term observations on the dynamics of bovine digital dermatitis lesions on a California dairy after topical treatment with lincomycin $\mathrm{HCl}$. Vet. J. 193:654-658. https://doi.org/10 $.1016 / j . t v j 1.2012 .06 .048$.

Biemans, F., P. Bijma, N. M. Boots, and M. C. M. de Jong. 2018. Digital Dermatitis in dairy cattle: The contribution of different disease classes to transmission. Epidemics 23:76-84. https://doi .org/10.1016/j.epidem.2017.12.007.

Braun, V., and V. Clarke. 2013. Successful Qualitative Research: A Practical Guide for Beginners. Sage, London.

Bruijnis, M., H. Hogeveen, C. Garforth, and E. Stassen. 2013. Dairy farmers' attitudes and intentions towards improving dairy cow foot health. Livest. Sci. 155:103-113. https://doi.org/10.1016/j.livsci 2013.04.005

Bruijnis, M. R. N., B. Beerda, H. Hogeveen, and E. N. Stassen. 2012. Foot disorders in dairy cattle: Impact on cow and dairy farmer. Anim. Welf. 21:33-40. https://doi.org/10.7120/ $096272812 X 13345905673601$.

Cheli, R., and C. Mortellaro. 1974. La dermatite digitale del bovino. Pages 208-213 in Proc. 8th Int. Conf. on Diseases of Cattle, Milan, Italy. Tipografia Editoriale Piacentina Gallarati, Piacenza, Italy.

Cook, N. B. 2006. Hygiene Scoring Color Chart. Accessed Jul. 22, 2020. https://www.vetmed.wisc.edu/fapm/wp-content/uploads/ 2020/01/hygiene.pdf.

Cook, N. B. 2017. A review of the design and management of footbaths for dairy cattle. Vet. Clin. North Am. Food Anim. Pract. 33:195-225. https://doi.org/10.1016/j.cvfa.2017.02.004.

Cramer, G., T. Winders, L. Solano, and D. H. Kleinschmit. 2018. Evaluation of agreement among digital dermatitis scoring methods in the milking parlor, pen, and hoof trimming chute. J. Dairy Sci. 101:2406-2414. https://doi.org/10.3168/jds.2017-13755.
Dolecheck, K., and J. Bewley. 2018. Animal board invited review: Dairy cow lameness expenditures, losses and total cost. Animal 12:1462-1474. https://doi.org/10.1017/S1751731118000575.

Döpfer, D., and J. Bonino Morlán. 2008. The paradox of modern animal husbandry and lameness. Vet. J. 175:153-154. https://doi $. o r g / 10.1016 / j . t v j 1.2007 .02 .013$.

Döpfer, D., A. A. H. M. ter Huurne, J. L. Cornelisse, A. J. A. M. van Asten, A. Koopmans, F. A. Meijer, Y. H. Schukken, I. Szakáll, W. Klee, and R. B. Bosma. 1997. Histological and bacteriological evaluation of digital dermatitis in cattle, with special reference to spirochaetes and Campylobacter faecalis. Vet. Rec. 140:620-623. https://doi.org/10.1136/vr.140.24.620.

Higginson Cutler, J. H., G. Cramer, J. J. Walter, S. T. Millman, and D. F. Kelton. 2013. Randomized clinical trial of tetracycline hydrochloride bandage and paste treatments for resolution of lesions and pain associated with digital dermatitis in dairy cattle. J. Dairy Sci. 96:7550-7557. https://doi.org/10.3168/jds.2012-6384.

Krull, A. C., J. K. Shearer, P. J. Gorden, V. L. Cooper, G. J. Phillips, and P. J. Plummer. 2014. Deep sequencing analysis reveals temporal microbiota changes associated with development of bovine digital dermatitis. Infect. Immun. 82:3359-3373. https://doi.org/ 10.1128/IAI.02077-14.

Moreira, T. F., E. J. Facury Filho, A. U. Carvalho, M. L. Strube, M. W. Nielsen, K. Klitgaard, and T. K. Jensen. 2018. Pathology and bacteria related to digital dermatitis in dairy cattle in all year round grazing system in Brazil. PLoS One 13:e0193870. https:// doi.org/10.1371/journal.pone.0193870.

Nielsen, M. W., M. L. Strube, A. Isbrand, W. D. H. M. Al-Medrasi, M. Boye, T. K. Jensen, and K. Klitgaard. 2016. Potential bacterial core species associated with digital dermatitis in cattle herds identified by molecular profiling of interdigital skin samples. Vet. Microbiol. 186:139-149. https://doi.org/10.1016/j.vetmic.2016.03 .003 .

Palmer, M. A., and N. E. O'Connell. 2015. Digital dermatitis in dairy cows: A review of risk factors and potential sources of between-animal variation in susceptibility. Animals (Basel) 5:512-535. https: //doi.org/10.3390/ani5030369.

Potterton, S. L., N. J. Bell, H. R. Whay, E. A. Berry, O. C. D. Atkinson, R. S. Dean, D. C. J. Main, and J. N. Huxley. 2012. A descriptive review of the peer and non-peer reviewed literature on the treatment and prevention of foot lameness in cattle published between 2000 and 2011. Vet. J. 193:612-616. https://doi.org/10 $.1016 / j . t v j 1.2012 .06 .040$.

Relun, A., R. Guatteo, M. M. Auzanneau, and N. Bareille. 2013. Farmers' practices, motivators and barriers for adoption of treatments of digital dermatitis in dairy farms. Animal 7:1542-1550. https://doi.org/10.1017/S1751731113000803.

Relun, A., R. Guatteo, P. Roussel, and N. Bareille. 2011. A simple method to score digital dermatitis in dairy cows in the milking parlor. J. Dairy Sci. 94:5424-5434. https://doi.org/10.3168/jds .2010-4054.

Ritter, C., J. Jansen, S. Roche, D. F. Kelton, C. L. Adams, K. Orsel, R. J. Erskine, G. Benedictus, T. J. G. M. Lam, and H. W. Barkema. 2017. Invited review: Determinants of farmers' adoption of management-based strategies for infectious disease prevention and control. J. Dairy Sci. 100:3329-3347. https://doi.org/10.3168/ jds.2016-11977.

Roche, S. M., D. F. Kelton, M. Meehan, M. Von Massow, and A. JonesBitton. 2019. Exploring dairy producer and veterinarian perceptions of barriers and motivators to adopting on-farm management practices for Johne's disease control in Ontario, Canada. J. Dairy Sci. 102:4476-4488. https://doi.org/10.3168/jds.2018-15944.

Schreiner, D. A., and P. L. Ruegg. 2002. Effects of tail docking on milk quality and cow cleanliness. J. Dairy Sci. 85:2503-2511. https:// doi.org/10.3168/jds.S0022-0302(02)74333-6.

Solano, L., H. W. Barkema, C. Jacobs, and K. Orsel. 2017a. Validation of the M-stage scoring system for digital dermatitis on dairy cows in the milking parlor. J. Dairy Sci. 100:1592-1603. https:// doi.org/10.3168/jds.2016-11365.

Solano, L., H. W. Barkema, E. A. Pajor, S. Mason, S. J. LeBlanc, J. C. Zaffino Heyerhoff, C. G. R. Nash, D. B. Haley, E. Vasseur, D. 
Pellerin, J. Rushen, A. M. de Passillé, and K. Orsel. 2015. Prevalence of lameness and associated risk factors in Canadian HolsteinFriesian cows housed in freestall barns. J. Dairy Sci. 98:6978-6991. https://doi.org/10.3168/jds.2015-9652.

Solano, L., H. W. Barkema, C. Pickel, and K. Orsel. 2017b. Effectiveness of a standardized footbath protocol for prevention of digital dermatitis. J. Dairy Sci. 100:1295-1307. https://doi.org/10.3168/ jds.2016-11464.

Vanhoudt, A., D. A. Yang, T. Armstrong, J. N. Huxley, R. A. Laven, A. D. Manning, R. F. Newsome, M. Nielen, T. van Werven, and N. J. Bell. 2019. Interobserver agreement of digital dermatitis Mscores for photographs of the hind feet of standing dairy cattle. J. Dairy Sci. 102:5466-5474. https://doi.org/10.3168/jds.2018-15644.

van Huyssteen, M., H. W. Barkema, S. Mason, and K. Orsel. 2020. Association between lameness risk assessment and lameness and foot lesion prevalence on dairy farms in Alberta, Canada. J. Dairy Sci. 103:11750-11761. https://doi.org/10.3168/jds.2019-17819.
Yeruham, I., and S. Perl. 1998. Clinical aspects of an outbreak of papillomatous digital dermatitis in a dairy cattle herd. J. S. Afr. Vet. Assoc. 69:112-115. https://doi.org/10.4102/jsava.v69i3.830.

Zinicola, M., F. Lima, S. Lima, V. Machado, M. Gomez, D. Döpfer, C. Guard, and R. Bicalho. 2015. Altered microbiomes in bovine digital dermatitis lesions, and the gut as a pathogen reservoir. PLoS One 10:e0120504. https://doi.org/10.1371/journal.pone.0120504.

\section{ORCIDS}

A. Vanhoudt (ํ) https://orcid.org/0000-0003-2122-3708

K. Orsel ๑ https://orcid.org/0000-0002-6499-5188

M. Nielen ๑ https://orcid.org/0000-0001-6909-877X

T. van Werven ๑ https://orcid.org/0000-0003-2391-0253 